\title{
ON METHODS OF SOCIAL RESEARCH IN PAKISTAN
}

\author{
S. M. HAFEEZ ZAIDI \\ Pakistan Acadenty for Village Development, Comilla
}

There are two general theoretical approaches to all psychological research. The first, attempts to study some limited aspect of behavior observed under controlled conditions. This permits accuracy and the use of quantitative techniques of measurement. This approach can use a very simple model of man. The second approach is more concerned with the analysis and explanation of responses as these occur in real life situations. Here interest centers round significant variables in social behavior. As pointed out by Katz and Stotland (7) the first approach is strong in method and weak in content, the second is weak in method but strong in content.

In the course of the past many decades the psychologists have predominantly been concerned with the first approach of controlled experimentation and have undoubtedly discovered a great deal about what might loosely be called "adaptive behavior" of organisms. The merit of the experimental approach is its ability to produce firm knowledge and to be relatively free of the non-scientific pressures of the practical conditions. But as Farrel points out "Much theorizing in psychology over the past 30 years has been mis-placed. Much of it has assumed that experimental psychology is strong enough to arrive at laws of behavior" (5). The limits of the experimental methods in psychology have not fully been appreciated. Not many psychologists have realized the vulnerability of their generalizations. Psychophysics may develop a sound body of findings but it may never become a substitute for a valid psychology of perception. Problems of human relations and behavior cannot be studied by separating groups and individuals as we do chemicals; neither can they be studied in the laboratory in the way it is done in the natural sciences.

Studies of social behavior in the real life drama, sprang up as a reaction against a general experimental psychology which found no place in its scheme for some of the most essential properties of man. Scientific psychology restricted its observations to the relation; between the individual and an evironment that strictly excluded other persons. It was not concerned with relations between persons or between persons and groups. The relatively new approach mainly employed by social psychologists assumes that psychology cannot be complete without directly looking at man as a social being.

It is not always possible in this approach to strictly adhere to the conventional independent-intervening-dependent variable frame work, as this does not do justice to the interactional character of social life and experience. Almost every phenomenon of an individual social life which is influenced by some factor also has some influence upon that factor. Perceptions are influenced by motivation and in turn social motives are influenced by perception. To hypothesize, therefore, that certain independent variables always influence certain dependent variables implies a non-interactional frame work which is not appropriate to explain the complexities of social life. In the actual life situations the independent and dependent 
variables may reverse roles. One may concede, however, that for operational purposes in controlled experinents the independent-dependent scheme is indispensable but at the theoretical level it may be more valid to conceive of an interactional system in a state of changing equilibrium but always moving towards balance.

\section{II}

Recently under the influence of social scientists in general, a considerable number of psychologists have started to include more extended social groups in their perview. Stimulated by new methodological tools like sociometry and group dynamics, psychologists have begun studies of leadership and other aspects of groups, functioning variously in clubs, play fields and discussion meetings. This increasing interest in community studies started during World War II and a number of significant studies during and after the war have really laid the foundation for adequate community research.

A historical review of community studies is relevant in the present context only in so far as these studies throw light on some methodological implications. It is true that none of these studies are comparable to our rural or urban communities except in so far as both involve group processes, interaction patterns, dynamics of leadership and a number of attitudes and prejudices peculiar to each community. As a result of this similarity of social pattern the Pakistani social psychologist is faced with more or less the same methodological problems as his western counterpart.

Almost all social psychological studies of community have used methods of observations different from controlled laboratory methods. Most of the facts on which social science studies are based, are collected from records and through direct observations by interview and surveys. A study of the literature indicates that the methods mostly derided by experimentally-oriented psychologists have proved most useful in community research. There have, however, been variations in the approach in terms of the particular interest of the investigator. For example, in the area of communication the focus has been the intensive analysis of mass media. Individuals within a large social structure are studied to find out how "interpersonal relations affect the impact of the media of public communication" (8). Another group of investigators interested in the study of attitude towards the community have mostly utilized interview techniques to see how the members feel about their community, its facilities and services. Others, more rigorous methodologically, have utilized properly standardized attitude questionnaires on an adequately sampled population. Still others have focused on variations within the community and also on comparative studies of different communities. Such studies have necessarily to depend more and more on accurate methods of quantitative measurements. Anthropologically-oriented studies of community have deeply relied on observations and case materials rather than quantitative data. There are many other studies where a combination of census type data, interviews, structured questionnaires and socio-economic indices have been employed.

Apparently there is not one proper approach to community research. The selection of techniques and methods would seem to be directly related to the specific professional orientation of the investigators. But as Sargent points out "One or both of two emphases, how- 
ever, are very likely to be found: (i) attention to individuals and individual differences against a background of group behavior, and (ii) concern with attitudes, feelings, awareness and the like rather than group behavior per se" (12).

Initially studies of communities were purely descriptive and methodologically unsophisticated concentrating mainly on the descriptions of "how people live" or "how people feel towards certain objects and situations" or "how people face certain community problems." But later studies reveai the growing sophistication in techniques, conceptualization and theoretical frames of reference; although more often these are implicit rather than explicit. In studies during the past 20 years or more, specifically after the war, concepts like social stratification and value and belief systems have been frequently employed and discussed. As Brunner (2) points out, community studies during the last 20 years have mainly progressed in three directions: there has been greater attention to the inter-relationship of factors within the comnunity; total complex of social organization has been examined; and finally there have been intensive community case-studies.

III

So much for a brief history of community research. Let us now examine two major theoretical frames of reference that have been employed in the studies of community; viz. 1) Community as an organism and (2) Community as a social system.

i) Community as an organism:

Within this theoretical frame work, a human society is "regarded as a definite kind of organism and its culture is conceived as those patterns of learned behavior which certain "parts" of the social organism characteristically display" (15). Most of the researches of social stress and consequent behavior disorganization have been conducted within this frame work. These have inveriably employed the concept of homeostasis (4) variously referred to as steady state, adjustment, balance, and equilibrium.

This view of society as an organism is based on the assumption that the community as an organization of living matter is definable as a network of inter-communication; in this view social organization exists to the degree that events in one subsystem are information to other subsystems (15).

There are, however, various difficulties in conceiving a community as an organism. The integration and interdependence in the various cells of a biological organism are much more compact and homogeneous than within the various subsystems of a community. Besides, the concept of balance or homeostasis in human organism is more clearly understandable than that within a community. Moreover, a society's various parts are more widely interchangeable, a person's only slightly so. Also the various subsystems in a community are more autonomous. The concept of community as an organism presents many such methodological difficulties. A community thought of as an organism will necessarily have to be less dynamic than all the community researches have conceived of it to be.

ii) Comnunity as a social system:

This theoretical position takes community to be a society in miniature encompassing 
all the major features of the society. Community is seen as representing "a system of stratification, a power structure, and characteristic institutions." All the major functions of the society are, therefore, sought within one single community at a limited scale. With this concept of community the generalizations about society as a whole become more valid and this provides valid justification for intensive and extensive studies of individual communities. Within this framework, investigators can ask questions which have wider applicability for the society. Methodologically such an approach is more fruitful both from the view points of applied and pure research.

Generalization in social sciences are never highly reliable but with the limited theoretical approach of community as an organism, it becomes more hazardous and even invalid to generalize the results of a community study for the whole society.

IV

In the context of Pakistan Society, community studies within the theoretical model of community as a social system promise great scientific possibilities. Assuming that we all recognize the need for social psychological study of our village society, it is only pertinent to discuss some of the significant aspects of such investigations. It may be added here that intensive studies of methodological difficulties and more likely to yield useful formulations about the dynamics of our rural society.

We are all aware that a certain informal institutional framework exists in most of the villages. This is variously named as panchayet, Biradari (Kinship group) or samiti. This sets the pattern of their mutual relationship as groups within the village community and also for interaction of individuals within the community and between one community and another. This institutional affiliation becomes quite sharp when individuals are faced with a choice situation as in accepting a new practice etc. In terms of community research, this organizational framework of village life in much too comprehensive and general; but may be helpful as a starting point for our analysis of the social fabric of rural community. Besides the general village social organization in each village there may be discovered a subsystem of organizations which regulage the life of sub-groups in the village. In terms of the above analysis, the lowest social group in the village will be the kinship group above an individual nuclear family group. Kinship influences may be one of the most significant factors in understanding village social organization.

Another important research implication may be discovered in the study of the pattern of behavior closely related to the system of values and beliefs help by the community. Furthermore, it may be noted that within each village community and inherent in the pattern of social organization is a pattern of authority embodying the process of decision making and the role of leadership.

Village factions:

One of the focal problems in the study of social organization is conflict. Those of us who have had contacts with Pakistan rural scene must be aware of such conflicts in our own social life. Village factions, as this phenomenon is sometimes referred to are fundamental to the understanding of the community life in rural Pakistan. A study of factions necessarily 
involves adequate understanding of the pattern of sub-group organization, pattern of behavior and the pattern of authority. It is because of its wide implication for the community that I have chosen to discuss, by way of illustration, village factions and the methodological difficulties the study has presented. In a recent study in India, Lewis (9) regards the study of factions as leading to the very heart of village life. The term faction here refers to "groups or sections of a society in relation of opposition to one another, interested in promoting their own objects rather than those of the society as a whole and often turbulent in their operations" (6). When factions occur, their membership is determined by the precise circumstances of their occurrence. Factions may not be permanent groups, but in most cases tend to persist for quite sometime leaving pretty durable traces in the social life of the community.

The observations that follow are based on intensive interviews by development officer trainees and also on first-hand observations of the social situation in the community under study. The data so far are not conclusive, but are presented here with a view to analyzing some of the methodological questions that have come up in the course of these observations.

The village has a population of 1300 out of which some 300 are Hindus. In all there are 350 family units. Agriculture is the main occupation, although a few families have some subsidiary occupations like shop-keeping and doing odd jobs in the neighboring town of Comilla. There are 24 Hindu weavers and two doctors who have certificates for practising medicine from a medical school. Educationally, the village is not backward. There are four intermediate passed, eight matriculates and two have read upto matric standard, besides the two doctors mentioned above.

There are three kinship groups besides the other villagers who are known as "Rayes". These families are Kazi, Munshi and Majumdar. Traditionally these and a few others are aristocratic Muslim families gencrally recognized in East Pakistan as possessing culture and refinement. In this village, however, these families do not enjoy any perceptible aristocratic status.

There seem to be two lines of authority in the village. Normally the leadership in villages is in the hands of Sardars and Maa'tbars. In this village besides three sardars there are two person leading two factional groups. It may be noted that the sardars have gone into a secondary leadership position because of the faction. There is no one accepted as the village leader. It is only the two faction leaders who are important to their respective group.

The context of events within which faction exists in this village are three. One of the leaders organized a youth club which then decided to start a primary school. Since the leader of the other factional group was not involved in the school management, he did not support it. One thing led to another. The school was proposed to be financed by the toll collected from the village market. The faction leader, opposed to the school, dissociated himself from the market and built a new one near his house. With the opening of a market a new prayer ground was built which was later on coverted into an Idgah. Thus the primary school led to a split in the market and building up of an additional Idgah. The faction now involves the whole village which is divided in its loyalty regarding i) Primary school; ii) village market and iii) Idgah. 
From our observation of a number of other villages, it becomes clear that factions are a basic aspect of traditional village social organization. The basis of a faction is normally a madrassah, a mosque, Idgah or some such community institution. More specifically, factions develop as a result of a) land disputes; b) aspiration for leadership of the village and the loss of prestige perceived by the contestants; $c$ ) quarrel over social ceremonies and functions; $d$ ) quarrel over marriage and divorce; e) controversy over religious rites; f) quarrel over management of public institutions; $g$ ) the presence of various interest groups in the community and $h$ ) the emergence of some new leaders because of newly-acquired wealth or education or any other prestigious qualification. It appears that in most cases it starts with a conflict between the old established leadership in the community and certain situations which are likely to disturb the equilibrium in the community power structure.

So this is the picture of a village which in many respects may be typical of East Pakistan rural scene. The question to be asked are: i) what in this situation would be relevant for a psychological study; ii) what methods of psychology can profitably be used for a study of this situation and iii) how reliable will such a study be for psychological theory. No one with the present state of our knowledge can answer these questions with any great conviction and reliability. All that we can do is to analyze and attempt to see how far our current psychological methods can help us in understanding the situation.

i) As to the first question regarding the relevance of faction study, it may be pointed out even at the risk of repetition that such a study, leads to the heart of our village society. It enables us to understand and predict the community pattern of behavior. This is specially important for programmes of social change whose success is based on how the people perceive the programme. Further, the proper psychological perspective in the study of factions is not the faction itself. Rather, it is the setting or, as Lewinians would call it, the "field" in which one can study behavior of individuals and the interconnections between social, economic and psychological processes. It is the study of group dynamics and how the disturbing forces impinge on the motivations, attitudes and perception of the members of the group; and how because of the factions, the interpersonal, intrapersonal, inter- and intragroup situations are modified. Factions can be a helpful adjunct to study of leadership, power structure and the pattern of authority in a community. Concepts like 'reference group' and 'communication channels' acquire proper perspective in a faction-ridden community.

ii) As to the second question regarding appropriate methods of study, it has been pointed out earlier that no one neither can be prescribed. Apparently experimental method as understood in terms of laboratory research cannot be applied in community studies. Nevertheless, tested principles of scientific methodology are applicable to all situations; the specific methods and techniques must be adapted to the socio-cultural setting. Statistical methods can certainly be of immense help in the selection of samples and in working out scales and schedules; but over-concern with coding techniques and accuracy of responses may lead one to make false inferences. Expecting our peasants to answer in 'yes' and 'no' is belied by experience.

Strict adherence to orthodox research procedure may not always pay in our rural setting. It might be necessary to have enough field experience before any research plan can be 
devised and even then there may always be unexpected situations in the light of which methods and the research design may have to be modified.

In the study of social behavior including factions, there would always be a number of variables which can be classified and investigated into even without going into the field. For example, information on economic demographic and ecological aspects of the community can be had from certain reliable sources. These can always be checked. These can serve as background for the analysis of the specific problems. For any community research, such background data are essential and cannot be overlooked.

Specifically for the study of factions, well-known techniques of "group dynamics" and sociometry are particularly relevant. Psychologists have also successfully used the analysis of written documents in their studies (1). In the study of factions this method can be used in the analysis of law-suits and other relevant records. Case-study, as Cottrell (3) has ably analyzed, with the social situation as the unit of description and analysis can also help a great deal. He has rightly pointed out that in psychology "our habitual focus of attention has been on individual persons and their alleged traits rather than on interact units of observation and description."

iii) As to the question regarding the reliability of our research data for psychological theory, it may be pointed out that psychology is still in a stage where there are either too many theories and too few facts to support these or there are too few theories and too many facts which are random and still unsystematized. Faction research may serve to clarify some of the facts in social psychology and will certainly throw light on problems of cross-cultural research. In this connection the following statement of Thoulcss is very reassuring. "All scientific study begins by the method of random observation and uses as its data the facts of common experience. The method of random observation of common experience is now generally derived as anecdotalism. The anecdotal stage is, however, one through which every science must pass. There was a time when physics was passing through the stage of "curious observations" on the behavior of shriveled apples under vacuum pumps and so on. The random observer in any field of science makes the preliminary survey which suggests the problems for later exact research" (14).

These somewhat random observations on methods and techniques for the study of social problems of the village society illustrate the difficulties of the research situation. The chief purpose of these observations was not to minimize the importance of laboratory research and its sound conclusions; neither was it to suggest that descriptive statements and indefinite observations may be a substitute for accurate measurement. It has been through out the paper, the attempt to make it clear that "both geographically and methodologically there are frontiers to our science and some of us must have courage enough to work on these frontiers rather than seek the safe haven of certain well-accepted, tried-and-true techniques" (11).

\section{REFERENCES}

1. Allport, G. W. The use of personal documents in psychological science. Social Science Research Conncil Bulletin, 1942, 49.

2. Brunner, E. The growth of a science. New York:
Harper \& Bros., 1957.

3. Cottrell, L. S., Jr. The case-study method in prediction. Socionetry, 1941, 4, 358-370.

4. Easton, D. Limits of equilibrium model in social 
research. Behatioral Science Publication No. 1, Chicago, 1953.

5. Farrell, B. A. On the limits of experimental psychology. Brit. J. Psychol., 1955, 46, 165-177.

6. Firth, R. Factions in Indian and Oversears Indian societies -- Introduction. Brit. J. Sociol., 1957, 8, 291-295.

7. Katz, D. \& Stotland, E. A preliminary statement to a theory of attitude structure and change. In S. Koch (Ed.) Psychology: A study of a science, Vol. 3. New York: McGraw Hill, 1959.

8. Leigh, R. D. Bennington communication study. (Mimeographed) Columbia University, 1953.

9. Lewis, O. Group dynamics in a North Indian village-A study of factions. Planning Commission, Government of India, New Delhi, 1954.

10. Reiss, A. J., Jr. The sociological study of com munities. In "Frontiers of community research and action." A symposium. Madison: Univ. of Wisconsin, 1958.

11. Sanders, I. T. Research with peasants in underdeveloped areas. Soc. Forces, 1956, 35, 1-10.

12. Sargent, S.S. Assessing community attitudes and social relations. In Sherif and Wilson (Eds.) Emerging problem in social psychology. Univ. of Oklahoma, 1957.

13. Thorndike, E. L. American cities and states. New York Academy of Science Annals, 1939, 39, 213-297.

14. Thouless, R. H. Scientific method in the study of the psychology of religion. Character $\mathcal{E}$ Pers., 1938, 7, 103-108.

15. Wallace, A. F. C. Revitalization movements: some theoretical considerations for their comparative study. Amer. Anthrop., 1956, 58, 264-281.

MS. received II 13,61 .

S. M. Hafeez Zaidi (1926- ) 1946-50 Muslim Univ. (Aligarth, India), MA; 1950-52, teaching staff, Univ. of Dacca (East Pakistan); 1952-55, Univ. of London, PhD; 1955-58, teaching and research staff, Univ. of Dacca; 1958. Social Psychologist to the Academy for Village Development (Government of Pakistan) at Comilla (East Pakistan) and 1959-60, I. C. A. participant in a Ford Found. project, at Michigan State Univ. 